SECTION 21. Pedagogy. Psychology. Innovations in the field of education.

Inna Ivanovna Kokhan

Senior lecturer,

Educational scientific professionally Pedagogical Institute of the Ukrainian Engineering Pedagogical Academy isa9@bk.ru

\title{
THE WAYS OF REALISATION OF THE TASKS OF THE AESTHETIC EDUCATION BY MEANS OF FOREIGN LANGUAGE AND CULTURE
}

Abstract: The article deals with the approaches to the realization of the tasks of the aesthetic education of the students by means of foreign language and culture. The components of the aestheticization of the process of foreign language study in higher educational establishment are determined. The pedagogical aspects of aesthetic development of student's personality during the studying of foreign language are considered.

Key words: aesthetic education, aesthetic development, the educative potential of a foreign language and culture.

\section{ПУТИ РЕАЛИЗАЦИИ ЗАДАНИЙ ЭСТЕТИЧЕСКОГО ВОСПИТАНИЯ СРЕДСТВАМИ ИНОСТРАННОГО ЯЗЫКА И КУЛЬТУРЫ}

Аннотация: $B$ статье рассмотрень подходы $\kappa$ реализаџии заданий эстетичного воспитания студентов средствами иностранного языка и культуры. Определены компоненты эстетизации процесса изучения иностранного языка в высшей школе. Рассмотрены педагогические условия, способствующие эстетическому развитию личности студента при изучении иностранного языка.

Ключевые слова: эстетическое воспитание, эстетическое развитие, воспитательный потенциал иностранного языка и культуры.

Особенностью развития современного общества являются процессы глобализации, которые приводят к сближению стран и народов, усилению взаимодействия, межнациональных контактов людей в различных, в том числе и профессиональной, сферах. Соответственно, это приводит к активизации поиска более эффективных методов и форм обучения и воспитания студенческой молодежи, подготовки к профессиональной деятельности в условиях многонациональной и поликультурной среды, межкультурного взаимодействия, требует повышения культуры общения и идентификации личности в поликультурном обществе [1].

Важную роль при этом приобретает деятельность высшей профессиональной школы, где формируются мировоззренческие основы, познавательные интересы, эстетические представления и характер поведения будущих специалистов при их включении в различные виды образовательной, общественной и профессиональной деятельности. В связи с этим, главной целью эстетического воспитания студенческой молодежи является воспитание эстетически развитой личности будущего специалиста, т.е. личности, имеющей «культурный стержень», обладающей эстетическим сознанием, характеризующейся развитым эстетическим вкусом, креативностью мышления и наличием способностей к реализации межкультурного диалога, а так же умением воспринимать и преобразовывать действительность по законам красоты во всех сферах жизнедеятельности.

Под понятием «эстетическое воспитание» мы подразумеваем целенаправленный, систематический процесс развития личности молодого человека, включающий 
усвоение культурных норм и системы ценностей страны изучаемого языка, развитие навыков эстетического восприятия искусства этой страны, формирование эстетических взглядов, чувств, вкуса, потребностей в создании прекрасного, а также развитие уважительного и ответственного отношения к культуре, открытость к диалогу культур и наличие необходимых умений для осуществления компетентного межкультурного общения.

Проблемы теоретических основ эстетического воспитания разрабатывались как педагогами-классиками (Я.Коменский, А.Макаренко, Й.Песталоцци, Г.Сковорода, В.Сухомлинский, К.Ушинский), так и современными учеными (В.Бутенко, И.Зязюн, Е.Квятковский, Л.Масол, Б.Неменский, Н.Падалка, Т.Рейзенкинд, Г.Шевченко и др.). Эстетическое воспитание молодых поколений средствами искусства слова исследовались Л.Айдаровой, О.Аксеновой, Л.Беленькой, М.Вашуленко, Н.Волошиной, С.Жупаниным, А.Капской, Е.Квятковским, В.Кононенко, М.Лещенко, А.Мазуркевичем, В.Мартиненко, О.Никифоровой, Н.Падалкой, З.Романовской, О.Савченко, Т.Цвелых, З.Шевченко и др. В работах этих ученых подчеркивается, что слово является весомым средством эстетического развития личности, формирования ее речевой и эстетической культуры. Общие вопросы организации эстетического воспитания студентов при изучении учебных дисциплин, в первую очередь, гуманитарного и художественного циклов глубоко исследованы в трудах В. Бутенко, Е.Крупник, Л.Масол , В.Мирецкой, Н.Миропольской, О.Торшиловой, Б.Юсова, Н.Саенко и др. [1-10]

В процессе интеграции Украины в европейское пространство и международное сообщество необходимым условием развития и профессионального успеха будущего специалиста является свободное владение иностранным языком, изучение которого имеет не только образовательную, но и воспитательную функцию. Очевидно, что воспитательный потенциал иностранного языка как учебной дисциплины открывает перед педагогом достаточно широкий спектр возможностей формирования эстетического сознания и эстетической культуры студента в единстве знаний, ценностных ориентаций, вкусов и идеалов, развития социокультурной компетенции, влияния на повышение уровня эстетики поведения, ориентирования на «диалог культур»; активизации творческого воображения, выработки потребности в творческой самореализации.

Определим совокупность основных компонентов, которые лежат в основе осуществления эстетизации процесса изучения иностранного языка в высшей школе. К ним относятся:

- эстетические аспекты содержания учебной дисциплины, требующие эстетического восприятия;

- культура мысли и красота слова, образность мышления, постоянное общение с искусством как средством познания и эстетических переживаний;

- эмоциональная насыщенность, изящество, эстетическая выразительность изложения учебного материала;

- эстетический мир, общая культура преподавателя и студента;

- эстетическая направленность взаимодействия преподавателя и студента, полное понимание и эстетические переживания при диалоговой форме общения;

- психологически комфортная, мажорная атмосфера в учебном процессе.

Эффективная организация процесса эстетического развития личности студента средствами иностранного языка и культуры должна основываться на определенных направлениях педагогической деятельности:

1. Определение эстетического аспекта в содержании дисциплины и соответствующая организация занятий с систематическим включением специально отобранных учебных материалов страноведческого характера, раскрывающих 
культурные, в том числе эстетические, особенности страны изучаемого языка (культура, искусство, национальные традиции и т.д.).

2. Применение особой педагогической технологии, направленной на активизацию эстетического отношения студентов к учебному процессу и к жизни в целом, в том числе и на разностороннее развитие личности студента а так же обеспечение соответствующих дидактических условий:

разработка профессионально ориентированных методических пособий для студентов, позволяющих акцентировать внимание на эстетическом аспекте текстов, в том числе специального назначения;

организация диалогической и монологической речи студентов, проведение ролевых игр, чтение текстов, направленных на развитие адекватных интонаций, эмоционального речевого общения на изучаемом языке, артистизма с включением эстетического критерия оценки действий и поведения участников занятия, создания личностно ориентированных ситуаций в обучении, которые требуют от студентов критического и проблемного мышления, оценочной и рефлексивной деятельности эстетического сознания и других компонентов эстетического развития личности;

развитие эстетического чувства через представление образности, выразительности, краткости языка на примерах поэтических, драматургических и прозаических произведений, обогащение иноязычной лексики (и соответствующего перевода на родной язык) национальными пословицами, поговорками, фразеологизмами с учетом уровня усвоения иностранной лексики студентами;

- подбор видео, аудио, киноматериалов культурно-эстетической направленности: применение наглядных пособий, технической аппаратуры и мультимедийных средств, иллюстрирующих произведения культуры и искусства страны изучаемого языка; прослушивание художественных текстов (поэзии, прозы, песен), озвученных носителями языка, с подчеркиванием эстетических критериев оценки интонации, богатства, выразительности речи, подготовка раздаточного материала, содержащего информацию о культуре и искусстве страны изучаемого языка;

- усиление эмоционально-оценочной составляющей взаимодействия педагога и студентов в процессе изучения иностранного языка.

3. Организация внеаудиторной и досуговой эстетической деятельности студентов, формирование направленности на эстетическое самообразование и самосовершенствование (встречи с носителями языка, участие студентов в научнопрактических конференциях с подготовкой докладов на иностранном языке, участие в различных студенческих конкурсах, тематических вечерах, заседаниях клубов, круглых столах, посещение культурологических лекций на иностранном языке, студенческих форумов и т.д.).

4. Обеспечение психологически комфортной, дружественной атмосферы на занятиях по иностранному языку.

Выбор и создание разнообразия форм эстетического воспитания студенческой молодежи средствами иностранного языка и культуры как традиционных, так и инновационных определяется творческим подходом педагогов высшей школы. Следует отметить, что на содержание, формы и методы эстетического воспитания в высших учебных заведениях Украины современного периода влияет структура ценностей общества, индивидуальные ценностные предпочтения и ценностные ориентации, духовные потребности студенческой молодежи, изучение эстетического опыта прошлого, историко-культурных традиций эстетического воспитания молодежи, осмысление эстетических аспектов собственной профессиональной деятельности. 
Эффективность условий эстетического воспитания студентов, по нашему мнению, проявляется в возникновении и формировании мотивационного интереса к освоению эстетических ценностей, потребности в продолжении эстетического образования и воспитания, трансформируясь в эстетическое самообразование, самовоспитание.

О результативности эстетического воспитания может свидетельствовать наличие таких факторов как создание качественно новой деятельности, обладающей высокими эстетическими достоинствами, привлекающей внимание окружающих; рождение творческой инициативы молодого специалиста; возрастание познавательной активности в смежных областях знаний и практической деятельности как своеобразный эффект творческого резонанса; появление нового аспекта ценностной ориентации; повышение уровня общей эстетической культуры личности молодого человека.

Подводя итоги, отметим, что полноценное использование воспитательного, образовательного и развивающего потенциала дисциплины «Иностранный язык» создает прочную основу для формирования личности творческого, эстетически развитого человека, не только практически владеющего иностранным языком, но и способным принимать активное участие в социально-экономическом и культурном развитии общества, а так же полноценно включатся в интегративные процессы, происходящие в современном мире.

\section{References:}

1. Бех І. Д. Духовна культуродомінантність як виховний ідеал : шлях досягнення / I. Д. Бех // Теоретико-методологічні проблеми виховання дітей та учнівської молоді : зб. наук. пр. - Вип.9, кн. 1 / за заг. ред. О. Додукіної. - К.-Житомир : Вид-во ЖДУ, 2006. - C. 6 - 25.

2. Вдович С. М. Естетизація навчального середовища як складова естетичного виховання особистості / С. М. Вдович // Креативна педагогіка : наук.-метод. зб. / Академія міжнародного співробітництва 3 креативної педагогіки. - Вінниця, 2010. Вип. 1. - С. 31 - 34.

3. Дерюгина И. В. Эстетическое воспитание студентов негуманитарных факультетов в процессе изучения иностранного языка. // Искусство в школе: М., 2008, №2. С 75-78.

4. Науково-педагогічна майстерня : науково-методичний посібник / за заг ред. О. I. Чернишова, Т. Б. Волобуєвої. - Донецьк : Витоки, 2008. - С. 125-136.

5. Миропольська Н. Э. Мистецтво слова в структурі художньої культури учня: теорія і практика. - К.: Парламентське видавництво, 2002. - 204c.

6. Саєнко Н.В. Культурологічний підхід до навчання іноземних мов у вищих технічних навчальних закладах : монографія / Н.В. Саєнко. - Харків : ХНАДУ, 2008. -344 с.

7. Харахоріна Т.О. Наукові розвідки про мову як витвір культури та особливості комунікативних практик суб'єктів навчальної діяльності // Наукова скарбниця освіти Донеччини.- № 2 (5). - 2009. - С.124-128.

8. Шевнюк О.Л. Культурологічна освіта майбутнього вчителя: теорія і практика : монографія /О.Л. Шевнюк. - К. : НПУ ім. М.П. Драгоманова, 2003. - 232 с.

9. Шевченко Г.П. Естетичне виховання у вищих навчальних закладах України у сучасний період / Г.П. Шевченко, Х.М. Джабер. - Луганськ: Вид-во СНУ ім. В.Даля, 2004. -208 c.

10. Korhonen K. E. Intercultural Competence as Part of Professional Qualifications. A Training Experiment with Bachelor of Engineering Students / K. E. Korhonen. - Jyvaskyla : University of Jyvaskyla, 2002. - 226 p. 